\title{
Protease activated receptor 1-induced glutamate release in cultured astrocytes is mediated by Bestrophin-1 channel but not by vesicular exocytosis
}

\author{
Soo-Jin Oh ${ }^{1}$, Kyung-Seok Han ${ }^{1,2}$, Hyungju Park' ${ }^{1}$, Dong ho Woo ${ }^{1,2}$, Hye Yun Kim¹', Stephen F Traynelis ${ }^{3}$ \\ and C Justin Lee $e^{1,2^{*}}$
}

\begin{abstract}
Background: Glutamate is the major transmitter that mediates the principal form of excitatory synaptic transmission in the brain. It has been well established that glutamate is released via $\mathrm{Ca}^{2+}$-dependent exocytosis of glutamate-containing vesicles in neurons. However, whether astrocytes exocytose to release glutamate under physiological condition is still unclear.

Findings: We report a novel form of glutamate release in astrocytes via the recently characterized $\mathrm{Ca}^{2+}$-activated anion channel, Bestrophin-1 (Best1) by $\mathrm{Ca}^{2+}$ dependent mechanism through the channel pore. We demonstrate that upon activation of protease activated receptor 1 (PAR1), an increase in intracellular $\mathrm{Ca}^{2+}$ concentration leads to an opening of Best1 channels and subsequent release of glutamate in cultured astrocytes.
\end{abstract}

Conclusions: These results provide strong molecular evidence for potential astrocyte-neuron interaction via Best1-mediated glutamate release.

Keywords: Astrocyte, Bestrophin-1, Glutamate

\section{Background}

Astrocytes and neurons are intimate partners in the brain. Astrocytes respond to neuronal activity by an increase in intracellular $\mathrm{Ca}^{2+}\left(\left[\mathrm{Ca}^{2+}\right]_{i}\right)[1,2]$. The synaptically released neurotransmitters such as glutamate and ATP activate corresponding $\mathrm{G}_{\alpha \mathrm{\alpha q}}$ protein-coupled receptors expressed in astrocytes, resulting in increase in $\left[\mathrm{Ca}^{2+}\right]_{\mathrm{i}}$ and $\mathrm{Ca}^{2+}$-dependent release of gliotransmitters from astrocytes [2,3]. These gliotransmitters in turn influence the neuronal excitability and synaptic activities [3-8].

At the heart of this neuron-glia interaction there is glutamate, which is released from neurons by synaptic vesicles to mediate neuron-to-glia communication and from astrocytes by various $\mathrm{Ca}^{2+}$-dependent mechanisms

\footnotetext{
* Correspondence: cjl@kist.re.kr

${ }^{1}$ Center for Neural Science and Center for Functional Connectomics, Korea Institute of Science and Technology (KIST), Seoul, South Korea

${ }^{2}$ Neuroscience Program, University of Science and Technology (UST),

Daejeon, South Korea

Full list of author information is available at the end of the article
}

to mediate glia-to-neuron communication $[9,10]$. Therefore, understanding how astrocytes release glutamate in $\mathrm{Ca}^{2+}$-dependent manner and how astrocytically-released glutamate regulates neuronal synaptic activity has been a major challenge. One line of accumulating evidence supports that astrocytes release glutamate by $\mathrm{Ca}^{2+}$ - and SNARE-dependent exocytosis mechanism [11], although this mechanism has been recently challenged [12]. It has been reported that glutamate released by SNAREdependent mechanism regulates hippocampal synapse between perforant path afferents and granule cells [13] or Schaffer Collateral afferent and CA1 pyramidal neurons [6] through $\mathrm{N}$-methyl-D-aspartic acid receptor (NMDAR) activation. Yet, astrocytes also express a combination of anion-permeable channels to move $\mathrm{Cl}^{-}$and large anions such as glutamate across membranes in response to specific physiological stimulations $[14,15]$, raising the possibility that astrocytes have a multiple glutamate release mechanisms. Although astrocytes under 
physiological conditions appear to possess a $\mathrm{Ca}^{2+}$ - and anion channel-dependent glutamate release mechanism $[10,16]$, until now this idea has not been directly demonstrated due to the lack of molecular evidence.

Bestrophin is the gene identified as the gene responsible for Best's vitelliform macular dystrophy and has been shown to encode a functional $\mathrm{Ca}^{2+}$-activated anion channel (CAAC) in nonneuronal tissue and peripheral neurons [17]. This Bestrophin-1 channel (Best1) is directly activated by submicromolar intracellular $\mathrm{Ca}^{2+}$ concentration and has an anion selective pore with single channel activities [17-24]. Recently, we have discovered that astrocytes express CAAC and that Best 1 encodes most of the CAAC in astrocytes [25]. This astrocytic CAAC showed a considerable permeability to large anions such as isethionate and glutamate [25]. In addition, we have recently demonstrated that Best1 channel mediates tonic GABA release from cerebellar glia by a direct permeation [26]. Therefore, we hypothesized that Best1 is the molecular identity of $\mathrm{Ca}^{2+}$-dependent anion channel that mediates glutamate release from astrocytes. Here we tested whether Best1 is an alternative $\mathrm{Ca}^{2+}$-dependent glutamate release mechanism in cultured astrocytes. To stimulate astrocytes more physiologically, we activated endogenous GPCRs by application of TFLLR [27] a selective peptide agonist of the protease activated receptor 1 (PAR1). We demonstrate that PAR1-induced glutamate release is mediated not by conventional vesicular exocytosis but by an activation of glutamate permeable anion channel Best1 in cultured astrocytes.

\section{Results}

PAR1-induced glutamate release is mediated by CAAC

It has been suggested that hippocampal astrocytes utilize an anion channel-dependent mechanism for $\mathrm{Ca}^{2+}$-induced glutamate release $[10,16]$. To confirm the anion channelmediated glutamate release from astrocytes, we performed an in vitro glutamate release assay using radioactive isotope-labeled glutamate $\left({ }^{3} \mathrm{H}\right.$-glutamate) in cultured hippocampal astrocytes (Figure 1A) [7]. To elicit intracellular $\mathrm{Ca}^{2+}$ increase and the subsequent release of glutamate in astrocytes, we used TFLLR to activate PAR1. We found that an application of TFLLR induced a significant glutamate release from cultured astrocytes (Figure 1B), which was inhibited by a pre-incubation of anion channel blockers, such as niflumic acid and flufenamic acid (Figure 1B) [28]. These results suggested that astrocytes utilize anion channel-dependent glutamate release mechanism.

\section{Best1 mediates a $\mathrm{Ca}^{2+}$-dependent glutamate release in cultured astrocytes}

We have recently demonstrated that Best1 channel is activated by intracellular $\mathrm{Ca}^{2+}\left(\mathrm{EC}_{50}=150 \mathrm{nM}\right)$ with considerable permeability to GABA [26]. To test whether $\mathrm{Ca}^{2+}$ - induced glutamate release is also mediated by Best1 in native astrocytes, we adopted a gene silencing tool using the short hairpin RNA (shRNA) specifically targeted to mouse Best1 transcript $[25,26]$. We recorded whole cell currents in cultured astrocytes under gramicidin-D perforated patch configuration (Figure $2 \mathrm{~B}$ ). We found the significant $\mathrm{Ca}^{2+}$-induced conductance carried by the efflux

A
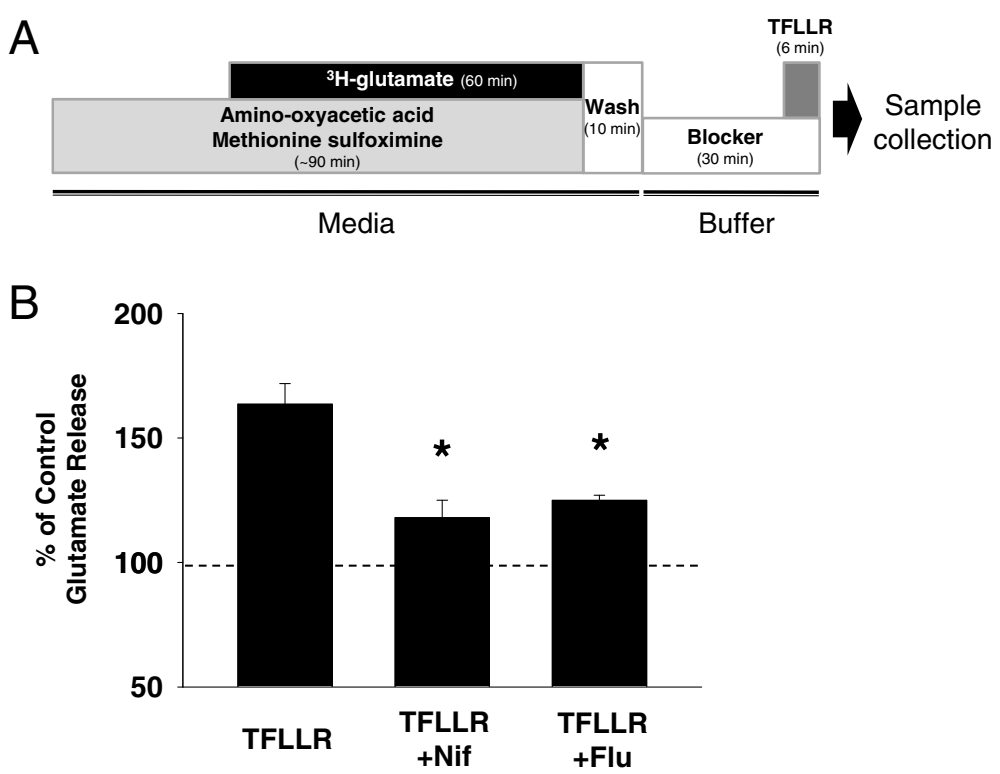

Figure 1 PAR1 induced glutamate release is blocked by CAAC blockers. A) The experimental scheme of in vitro glutamate release assay using isotope-labeled glutamate ( ${ }^{3} \mathrm{H}$-glutamate). $30 \mu \mathrm{M}$ of TFLLR was treated for 6 min to induce glutamate release from cultured astrocytes. B) Bar graphs represent the averaged relative amount of released glutamate by TFLLR treatment ( $n=12)$. $100 \mu M$ of Niflumic acid (Nif, $n=11)$ or Flufenamic acid (Flu, $n=4$ ) was pretreated to block anion channel activation. ${ }^{* *} \mathrm{p}<0.05$ vs. TFLLR-treated group. 


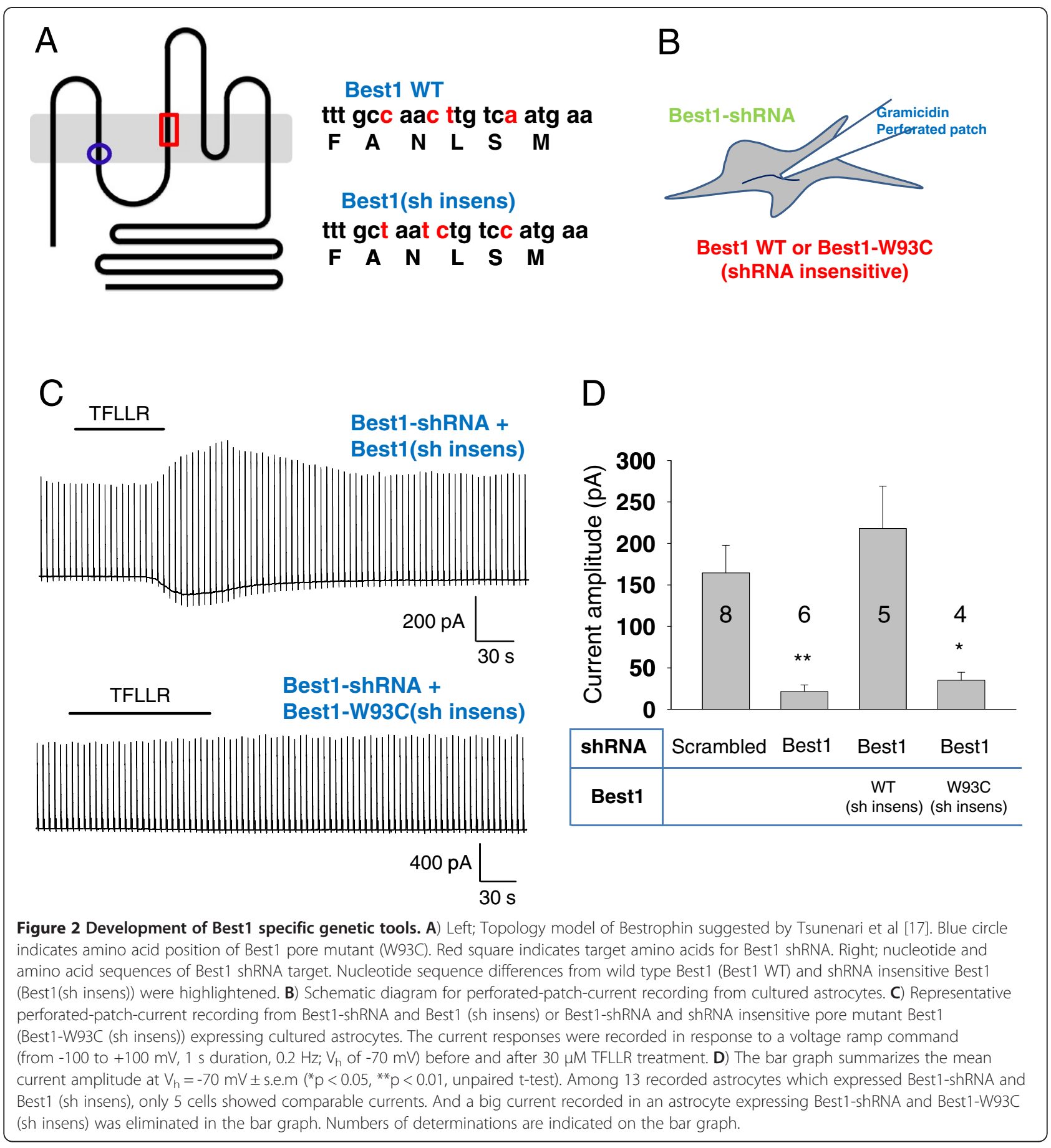

of glutamate at $-70 \mathrm{mV}$ in astrocyte with scrambledshRNA. Silencing the Best1 gene via specific shRNA for Best1 significantly eliminated PAR1 induced whole-cell current in cultured astrocytes. This effect was fully rescued by the cotransfection of Best1-shRNA, along with a shRNA-insensitive form of Best1 (Figure 2C and D). However, the addition of a pore mutation at position 93, from tryptophan to cystein (Best1-W93C sh insens) [29] failed to rescue the current (Figure $2 \mathrm{C}$ and $\mathrm{D}$ ). These results indicate that pore of Best1 channel is responsible for the permeation of anions such as $\mathrm{Cl}^{-}$and glutamate. We further tested the effect of Best1-shRNA on glutamate release using conventional high-performance liquid chromatography (HPLC) from the solution samples collected after 5 min application of TFLLR in cultured astrocytes. In this experiment, we firstly prepared astrocytes with the same cell number of cells that were transfected with Sc-shRNA or Best1-shRNA. Since we found that Best1-shRNA did 
not affect astrocytic cell growth or survival (data not shown), we assumed that total number of astrocytes in each sample after transfection of Sc-shRNA or Best1-shRNA should be similar. We found a decrease in glutamate release by Best1-shRNA using HPLC method (Figure 3). These results indicate that the Best1 channel is the molecular identity of glutamate permeable CAAC and suggest that the Best1 channel might be the molecular machinery for $\mathrm{Ca}^{2+}$-dependent glutamate release from astrocytes.

To independently confirm the glutamate release by HPLC method, we tested the effect of Best1-shRNA on glutamate release using fluorescence resonance energy transfer (FRET) based glutamate sensor. The released glutamate was monitored using a glutamate-sensing fluorescent reporter, GluSnFR, which senses glutamate by changing the ratio of FRET from CFP to YFP upon glutamate binding [30] (Figure 4A). The concentration-response curve for glutamate on the sensor was within the range of estimated glutamate release from a single astrocyte in culture $\left(\sim 10^{-6} \mathrm{M}\right)$ [7] (Figure 4C and 4D). The calculated $\mathrm{EC}_{50}$ of glutamate was $\sim 25.57 \mu \mathrm{M}$ (Figure 4D). We observed that a brief pressure application of TFLLR caused a long lasting glutamate release as indicated by the relative change in FRET ratio (Figure $4 \mathrm{~B}$ and $4 \mathrm{E}$ ). The amount of glutamate release was on average significantly lower in the astrocytes expressing Best1-shRNA (Figure 4E, red symbols) than those expressing control scrambled shRNA (Figure 4E, black symbols). We found a similar degree of decrease in glutamate release by Best1-shRNA using the FRET based glutamate imaging, as compared to HPLC method (Figures 3C and 4F). Co-application of TFLLR and niflumic acid or treating the cells with BAPTA-AM, significantly reduced the glutamate release from astrocytes (Figure 4E and 4F).

\section{PAR1 induced glutamate release is not due to vesicular release}

We noted that the amount of released glutamate was not completely inhibited by gene-silencing of Best1 (Figure $4 \mathrm{E}$ and $4 \mathrm{~F}$ ), raising a possibility that astrocytes have other Best1-independent mechanisms for glutamate release such as vesicular exocytosis. It is possible that Best1-shRNA affects the expression level of other genes involved in vesicular release. To address this possibility, we performed semi-quantitative RT-PCR analysis of cultured astrocytes with Best1-shRNA. Best1-shRNA showed a knock down efficiency for Best1 of over 90\% while not affecting the expression level of other known genes such as Syt4 (Synaptotagmin4), Munc18-1, Vamp2 (Vesicle-associated membrane protein 2) involved in vesicular release (Figure 5A). We also tested whether inhibiting vesicular release machinery affects the glutamate release by using FRET based glutamate imaging. We found that the pretreatment with Conconomycin A (preventing vesicular glutamate release by inhibiting vesicular hydrogen ATPase, [31]) and Tetanus toxin (interfering all vesicular releases by inhibiting fusion of vesicles, [32]) slightly but not significantly reduced TFLLR-induced glutamate release from cultured astrocytes (Figure 5B and 5C). Consistent with these results, hyperosmotic challenge, which is known to cause a $\mathrm{Ca}^{2+}$ independent exocytosis of glutamate containing releasable vesicles, did not show any significant increase in glutamate release (Figure $5 \mathrm{~B}$ and $5 \mathrm{C}$ ). Taken together, PAR1-induced glutamate release is not mediated by vesicular exocytosis in cultured astrocytes.

\section{Discussion}

In this study we report the direct evidence of anion channel-mediated glutamate release mechanism. We provide a series of evidence for $\mathrm{Ca}^{2+}$-activated, Best1-mediated glutamate release from astrocytes. For example, the selective gene silencing of astrocytic Best1 channels significantly reduced GPCR-induced and $\mathrm{Ca}^{2+}$-dependent glutamate release from astrocytes as measured by HPLC detection of glutamate from cultured astrocytes (Figure 3), and by FRET glutamate sensor in cultured astrocytes (Figure 4). The FRET based glutamate sensor has been wellcharacterized in the previous report [30]. In that report it has been demonstrated that FRET change is quite specific
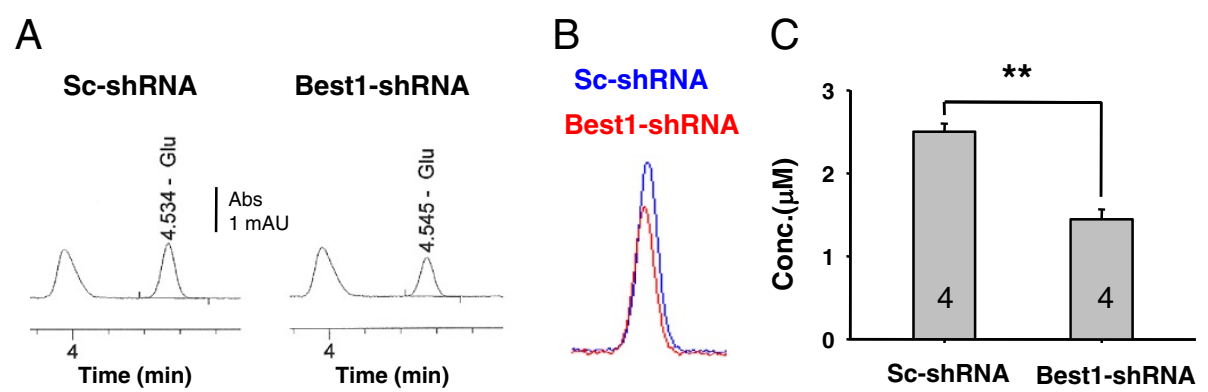

Figure 3 HPLC detection of TFLLR-induced glutamate release from astrocytes. A) The raw traces of HPLC detection of TFLLR-induced glutamate release from scrambled-shRNA (Sc-shRNA) or Best1-shRNA expressing cultured astrocytes. B) The merged traces are from Sc-shRNA (blue) and B1-shRNA (red) infected astrocytes. C) Bar graphs show the averaged HPLC-detected glutamate peak level. ${ }^{* *} \mathrm{p}<0.01$. 


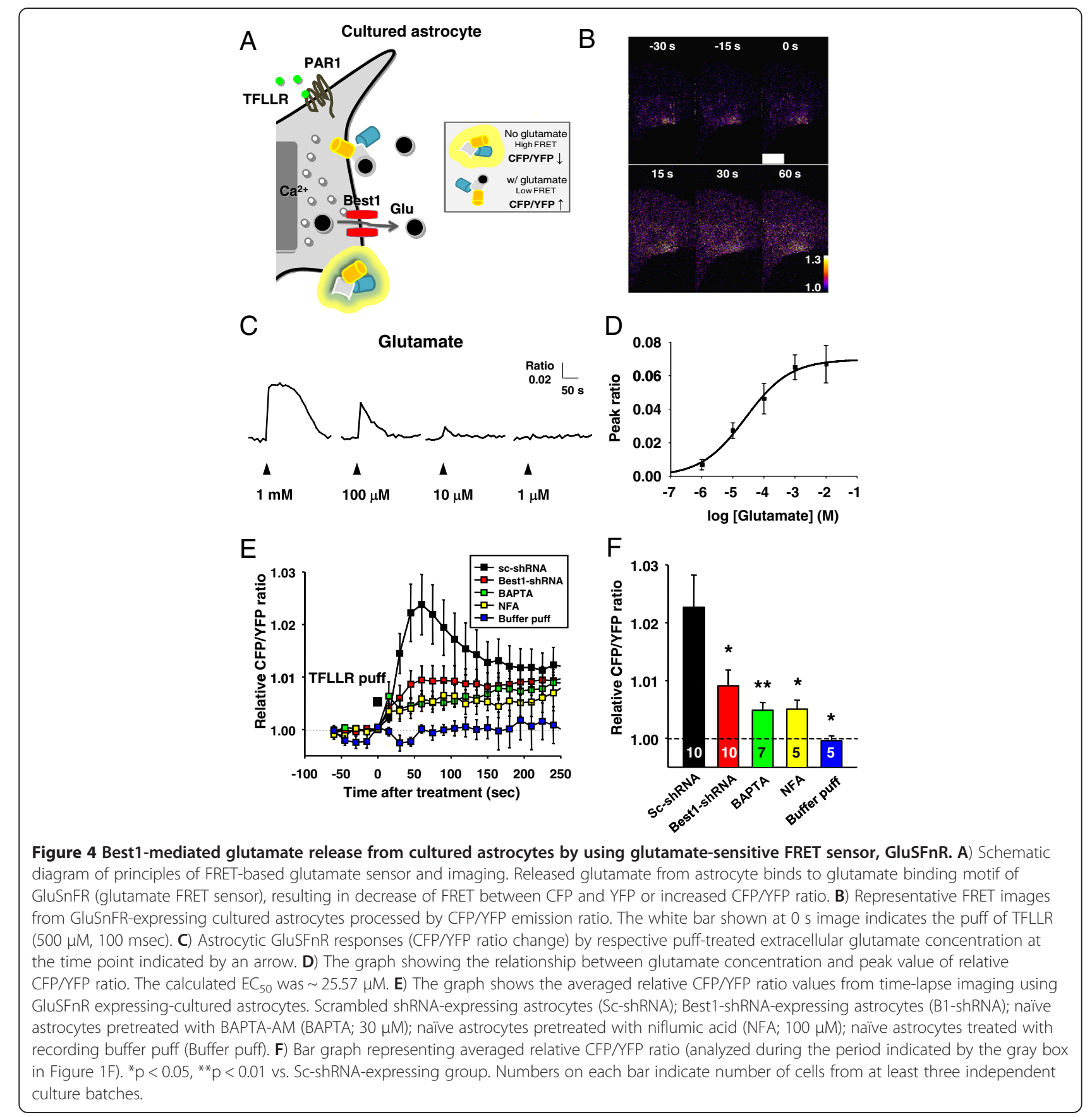

for glutamate because the sensor shows binding kinetics and high selectivity toward glutamate with no apparent change in ratio with APV, NBQX, NMDA, KA, AMPA, etc. [30]. We performed a calibration experiment by measuring glutamate $\mathrm{EC}_{50}$ in our imaging system and experimental conditions. Our calibration results showed that the FRET-based glutamate sensor in cultured astrocyte can be useful in detecting micromolar and submicromolar concentrations of released extracellular glutamate from a single astrocyte.
Until now, it has been proposed that glutamate could be released from astrocytes through multiple routes, including $\mathrm{Ca}^{2+}$ - and SNARE-dependent vesicular exocytosis, the reversal action of glutamate transporters, transportation by cystine-glutamate antiporter, and permeation through channels or receptors, such as P2X7 receptor, volume regulated anion channel (VRAC), or gap junction hemichannel [33]. Among these, the molecular mechanism of $\mathrm{Ca}^{2+}$-dependent glutamate release has been extensively studied mainly because the 

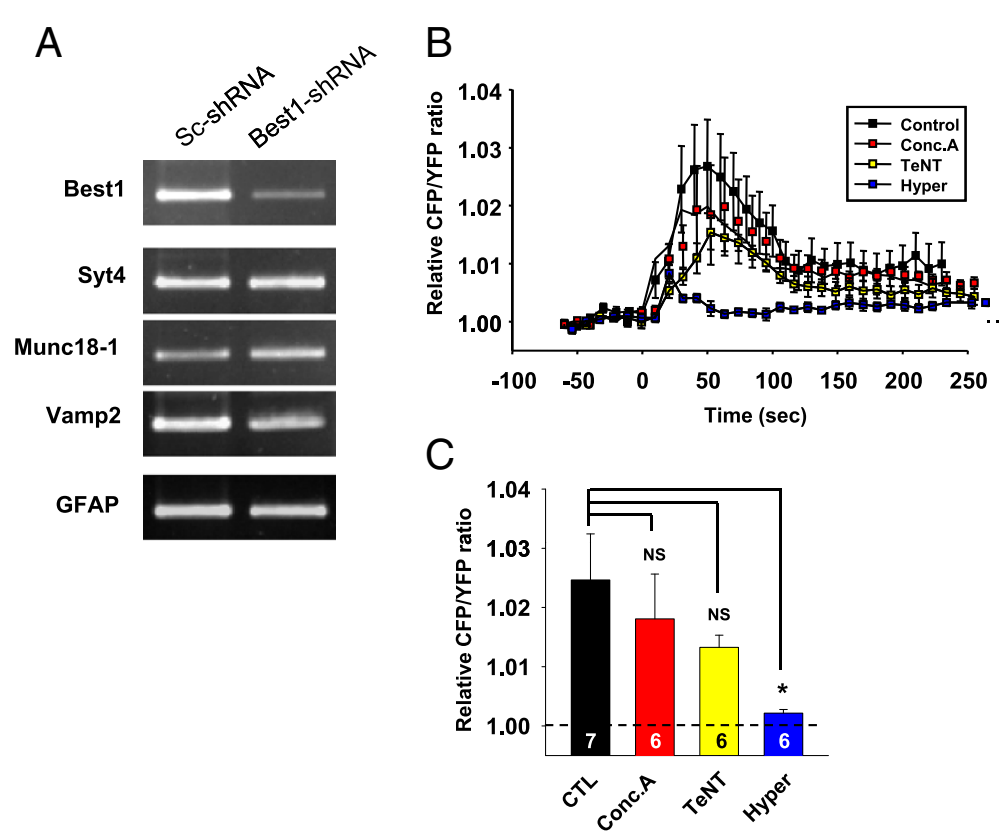

Figure 5 TFLLR-induced glutamate is not by vesicular exocytosis. A) To test whether Best1-shRNA affects the expression of exocytotic protein transcripts, mRNA expression levels of several endogenous vesicular machineries such as Syt4, Munc18-1, Vamp2 were analyzed from cultured astrocytes expressing Best1-shRNA or scrambled shRNA at least for 72 h. PCR cycles for Best1, Syt4 (Synaptotagmin4), Munc18-1, Vamp2 (Vesicle-associated membrane protein 2), and GFAP were 35, 35, 30, 30, and 25, respectively. B) Time-lapse imaging of relative CFP/YFP ratio from GluSFnR-expressing cultured astrcytes plotted as mean \pm sem. Arrowhead indicates the time point of $500 \mu \mathrm{M}$ TFLLR puff. Naïve astrocytes (Control); naïve astrocytes pretreated with $0.5 \mathrm{mM}$ concanamycin (Conc.A; 2 hrs); naïve astrocytes pretreated with $10 \mathrm{nM}$ tetanus toxin (TeNT; 14 hrs); naïve astrocytes treated with hyperosmotic solution puff (Hyper). Bar graphs represent the averaged relative CFP/YFP ratio from $30 \mathrm{sec}$ to $70 \mathrm{sec}$. Numbers of cells from at least two independent culture batches are indicated on the bar graph.

generation of astrocytic $\mathrm{Ca}^{2+}$ transient responding to neuronal activity is one of the most important physiological readout of neural activity $[3,5,7,10]$. Numerous studies have proposed the SNARE-dependent exocytosis of glutamate as a potential route for astrocytic $\mathrm{Ca}^{2+}$ dependent glutamate release. These studies demonstrated that astrocytic glutamate release was sensitive to exocytosis blockers or the expression of the essential machineries for regulating $\mathrm{Ca}^{2+}$-dependent exocytosis [33]. In addition to the vesicular mechanism, there is multiple lines of evidence suggesting that astrocytes express a $\mathrm{Ca}^{2+}$-dependent but non-vesicular glutamate release machinery [16]. Despite its unclear molecular identity, it has been reported that an increase in $\mathrm{Ca}^{2+}$ by GPCR activation induces glutamate release from astrocytes through osmolyte-permeable anion channels $[10,28]$, which are activated by intracellular $\mathrm{Ca}^{2+}$ or increase in cell volume [16]. In our previous reports, we observed that Best1-mediated $\mathrm{Ca}^{2+}$-activated anion current could be induced by a host of GPCR agonists such as mGluR1/5, P2Y, B2, S1P, and LPAR in astrocytes [25], and that activation of those receptors elicits $\mathrm{Ca}^{2+}$ dependent glutamate release [7]. Finally, Best1 was demonstrated to be permeable to GABA and mediate tonic GABA release in cerebellar glial cells [26]. Recent study showed that GABA is abundant in cerebellar glial cells to be released tonically via Best1 to cause tonic inhibition [34]. However, in hippocampus, GABA is not present in glial cells; rather, Best1 might release glutamate near synapse. Therefore, it is plausible that Best1, at least in part, could be the downstream target of various $\mathrm{G}_{\mathrm{q}}$-coupled GPCRs that signal through intracellular $\mathrm{Ca}^{2+}$ to release glutamate in hippocampal astrocytes.

In addition to Best1 channel, other anion channels might participate in anion channel-mediated glutamate release as previously suggested, such as $\mathrm{Ca}^{2+}$-induced but volume regulated osmolyte-permeable channels [16]. In fact, there are several studies showing that bestrophin channel could be opened by both cytosolic $\mathrm{Ca}^{2+}$ and cell volume increase $[17,35]$, raising a possibility that Best1-mediated glutamate release is also triggered by $\mathrm{Ca}^{2+}$-dependent cell swelling and subsequent activation of VRAC. However, in our previous study we demonstrated that PAR-1 activation does not induce significant swelling [36] indicating that $\mathrm{Ca}^{2+}$ directly initiates Best1 channel-mediated glutamate release from astrocytes. The PAR1-induced astrocytic glutamate release was not completely inhibited by Best1 knock-down (Figure 4). Still, vesicular release mechanism was not involved because Best1 silencing did not affect the expression level 
of known genes involved in vesicular release (Figure 5A) and glutamate release from astrocytes was not reduced by treatment with Conconomycin A or Tetanus toxin (Figure 5B). There is a possibility that other ion channels that are independent of Best1 channel might participate in PAR1-induced glutamate release from astrocytes.

We utilized the native GPCR, PAR1, which has been extensively used in numerous studies to selectively activate astrocytes. Even though PAR1 is expressed in a subset of dentate granule cells [37], PAR1 has been shown to be expressed exclusively in astrocytes in human and rodent CA1 hippocampus $[7,38,39]$, as well as in the nucleus of solitary tract [40] to mediate neuron-glia interaction. Therefore, the source of PAR1-induced glutamate is most likely astrocyte, as a direct consequence of increase $\left[\mathrm{Ca}^{2+}\right]_{\mathrm{i}}$. Although there is no direct evidence of how PAR1 is activated in the physiological situation up to now, the recent study demonstrated that tPA-plasmin pathway is an endogenous PAR1 agonist [41], suggesting that physiological PAR1 activation is initiated by the activation of tPA-plasmin pathway in physiological condition such as synaptic plasticity $[42,43]$.

In summary, we reveal a novel anion channel-mediated glutamate release mechanism in cultured astrocytes. The ideas and tools developed in this study should prove to be helpful in understanding the physiological role of glutamate release mechanism and its functional significances.

\section{Methods}

\section{Primary astrocyte culture}

Cell culture of mouse astrocytes was performed as previously described [7]. The cerebral cortex from P0 P3 postnatal mice was dissected free of adherent meninges, minced and dissociated into single cell suspension by trituration. Dissociated cells were plated onto $12 \mathrm{~mm}$ glass coverslips coated with $0.1 \mathrm{mg} / \mathrm{ml}$ poly D-lysine. Cells were grown in DMEM supplemented with $25 \mathrm{mM}$ glucose, $10 \%$ heat-inactivated horse serum, $10 \%$ heatinactivated fetal bovine serum, $2 \mathrm{mM}$ glutamine, and 1000 units ml-1 penicillin-streptomycin. Cultures were maintained at $37^{\circ} \mathrm{C}$ in humidified $5 \% \mathrm{CO}_{2}$-containing atmosphere.

\section{Glutamate FRET imaging}

In FRET-based glutamate imaging experiments, pDisplayGluSnFR vector [30] was electroporated alone or with pSicoR-scrambled-shRNA or pSicoR-Best1-shRNA vector into cultured astrocytes (MicroPorator; Digital Bio, Korea). After $48 \sim 72$ hour expression, FRET imaging was performed under a microscope (BX50WI; Olympus) equipped with xenon lamp with 436/20 excitation filter (D436/20x filter; Chroma). The emission beam was split with a DualView (Optical Insights) with a CFP/YFP filter set (OI-05-EX), recorded by EM-CCD camera (ANDOR IXON). Imaging
Workbench software (INDEC BioSystems) was used for image acquisition and offline image analysis. TFLLR puff (TFLLR-NH $\mathrm{N}_{2}$; Peptron, Korea; $500 \mu \mathrm{M}$ ) was made by using picospritzer-assisted positive pressure ( 100 ms). The amount of released extracellular glutamate was described as ratio between the emission intensity of CFP and YFP (CFP/ YFP), which was divided by baseline CFP/YFP ratio (relative CFP/YFP ratio).

\section{Radioactivity glutamate release assay}

In vitro glutamate assay using ${ }^{3} \mathrm{H}$-labelled glutamate was performed as described previously [7]. Astrocytes were

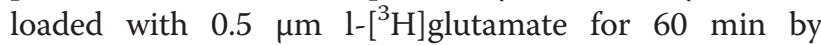
adding $1 \mu \mathrm{m}$ of $1 \mathrm{mCi} \mathrm{ml}^{-1} \mathrm{l}-\left[{ }^{3} \mathrm{H}\right]$ glutamate stock solution to $2 \mathrm{ml}$ of culture medium. The cultures were preincubated for $30 \mathrm{~min}$ with $1 \mathrm{~mm}$ amino-oxyacetic acid and $0.5 \mathrm{~mm}$ methionine sulfoximine before adding $\left[{ }^{3} \mathrm{H}\right]$ glutamate, and during the loading to inhibit the metabolism of glutamate to glutamine and other metabolites [44]. Cells were washed with external solution 3 times. In some experiments, the external solution was supplemented with $50 \mu \mathrm{m}$ l-transpyrrolidine-2,4-dicarboxylic acid (trans-PDC) to block glutamate transporter, a maximally effective concentration $\left(6 \times \mathrm{IC}_{50}\right.$ of $4-8 \mu \mathrm{m}$; [45]) that is well below that suggested to stimulate heteroexchange $(0.2 \mathrm{~mm} ;[46,47])$. Agonists were added to external solution for $6 \mathrm{~min}$ and the experiment was terminated by collection of the solution. Each experimental run included the control condition in which no agonist was added. Six replicates were obtained for each drug condition. For analysis, the average radioactivity count was obtained from six replicates for each condition and compared to the average of control.

\section{HPLC analysis for glutamate release}

The Cortical primary astrocytes were cultured in $60 \mathrm{~mm}$ dishes for HPLC analysis. TFLLR $(30 \mu \mathrm{M})$ was used to induce glutamate. Prior to TFLLR treatment, astrocytes were washed with PBS three times. For gene silencing experiment, Lentivirus containing Scrambled or Best1-shRNA was treated to cells and incubated for $48 \mathrm{hrs}$. The amino acid content was derivatized with $o$-phthaldialdehyde (OPA) and detected using UV (DAD) detection [48]. The OPA derivatized samples by programmed autosampler were injected on Zorbax Eclipse Plus $\mathrm{C}_{18}$ column with detection at $338 \mathrm{~nm}$ (a reference $=390 \mathrm{~nm}$ ). Mobile phase A was $40 \mathrm{mM} \mathrm{Na} 2 \mathrm{HPO}_{4} \mathrm{pH}$ 7.8 , and $\mathrm{B}$ was acetonitrile/methanol/water (45:45:10, v/v/v). The flow rate was $2 \mathrm{~mL} / \mathrm{min}$ with a gradient condition that allowed for $1.9 \mathrm{~min}$ at $0 \% \mathrm{~B}$ and raised to $26 \% \mathrm{~B}$ at a 12.5 min-step. Then washing at $100 \% \mathrm{~B}$ and equilibration at $0 \% \mathrm{~B}$ was performed in a total retention time of $15 \mathrm{~min}$. Reagents of OPA derivatization and all equipments for HPLC analysis were obtained from Agilent Technologies. 


\section{Lentivirus with Best1-shRNA and Best1 mutagenesis}

Best1-shRNA and lentivirus production were performed as previously described ([49], Virus facility, KIST). Best1 shRNA-insensitive pore mutant (Best1-shRNA insens W93C) was generated by using PCR-based site-directed mutagenesis kit (Stratagene, Cedar Creek, TX, USA).

\section{Electrophysiology}

The extracellular recording solution for perforated patch clamp recording was comprised of (in $\mathrm{mM}$ ) $150 \mathrm{NaCl}$, 10 HEPES, $3 \mathrm{KCl}, 2 \mathrm{CaCl}_{2}, 2 \mathrm{MgCl}_{2}, 5.5$ glucose, at $\mathrm{pH}$ 7.3. The internal solution contained $25 \mu \mathrm{g} / \mathrm{ml}$ gramicidin $\mathrm{D}$ and (in $\mathrm{mM}$ ) $75 \mathrm{Cs}_{2} \mathrm{SO}_{4}, 10 \mathrm{NaCl}, 0.1 \mathrm{CaCl}_{2}$, and 10 HEPES, at $\mathrm{pH}$ 7.1. Pipette resistances ranged from 5 to $8 \mathrm{M} \Omega$. It took 20 to $30 \mathrm{~min}$ to achieve acceptable perforation, with final series resistances ranging from 15 to $40 \mathrm{M} \Omega$. Current voltage curves were established by applying 100- , 200-, or 1000 ms duration voltage ramps from -100 to $+100 \mathrm{mV}$. Data were acquired by an Axopatch 200A amplifier controlled by Clampex 9.2 via Digidata 1322A data acquisition system (Axon Instruments, Union City, CA, USA). Experiments were conducted at room temperature $\left(20 \sim 24^{\circ} \mathrm{C}\right)$.

\section{Reverse transcription-PCR}

Total RNA was prepared from cultured astrocyte from postnatal day 0-3 mice using Trizol reagent (Invitrogen). cDNA was synthesized using Super Script III reverse transcriptase (Invitrogen). The reverse transcription (RT)-PCR primers used to check expression of Best1, Syt4 (Synaptotagmin4), Munc18-1, Vamp2 (Vesicle-associated membrane protein 2) GAPDH and glial fibrillary acidic protein (GFAP) were as followings

; Best1 forward, 5'-AGGACGATGATGATTTTGAG- 3' ; Best1 reverse, 5'-CTTTCTGGTTTTTCTGGTTG- 3' ; Syt4 forward, 5'-AGGCCAATTCCCCTGAGAGC- 3' ; Syt4 reverse, 5'-ACCGCTTCCTTCTGCTGTGG- 3'

; Munc18-1 forward, 5'-

ACTCCGCTGACTCTTTCCAA- 3'

; Munc18-1 reverse, 5'GTCGGCTTTATAGGCATCCA- 3'

; Vamp2 forward, 5'-GTCACTGCCTCTGCCAAGTC- 3' ; Vamp2 reverse, 5'-GGCAGACTCCTCAGGGATTT- 3' ; GAPDH forward, 5'-

AGCTGAACGGGAAGCTCACT- 3'

; GAPDH reverse, 5'-TGCTGTAGCCAAATTCGTTG- 3' ; GFAP forward, 5'-AGAACAACCTGGCTGCGTAT-3' ; GFAP reverse, 5'-CGGCGATAGTCGTTAGCTTC-3'

Primers for Syt4, Munc18-1 and Vamp2 were designed as previous reports [50,51]. All reactions were performed in a programmable thermocycler (Eppendorf).

\section{Competing interests}

The authors declare that they have no competing interests.

\section{Authors' contributions}

SJO performed patch clamp recording and wrote the manuscript. HP and KSH carried out FRET imaging experiments. DW and HYK performed HPLC analysis. SFT designed the radioactivity glutamate release assay experiment. CJL carried out radioactivity glutamate release assay and wrote the manuscript, and supervised entire project. All authors read and approved the final manuscript.

\section{Acknowledgements}

This work was supported by the National Research Foundation of Korea (NRF) grant funded by the Korea government (MEST) (No. 314-2008-1C00341).

\section{Author details}

${ }^{1}$ Center for Neural Science and Center for Functional Connectomics, Korea Institute of Science and Technology (KIST), Seoul, South Korea. ${ }^{2}$ Neuroscience Program, University of Science and Technology (UST), Daejeon, South Korea. ${ }^{3}$ Department of Pharmacology, School of Medicine, Emory University, Atlanta, GA, USA.

Received: 28 September 2012 Accepted: 9 October 2012 Published: 12 October 2012

\section{References}

1. Wang X, Lou N, Xu Q, Tian GF, Peng WG, Han X, Kang J, Takano T, Nedergaard M: Astrocytic Ca2+ signaling evoked by sensory stimulation in vivo. Nat Neurosci 2006, 9(6):816-823.

2. Haydon PG, Carmignoto G: Astrocyte control of synaptic transmission and neurovascular coupling. Physiol Rev 2006, 86(3):1009-1031.

3. Halassa MM, Fellin T, Haydon PG: The tripartite synapse: roles for gliotransmission in health and disease. Trends Mol Med 2007, 13(2):54-63.

4. Pascual O, Casper KB, Kubera C, Zhang J, Revilla-Sanchez R, Sul JY, Takano H, Moss SJ, McCarthy K, Haydon PG: Astrocytic purinergic signaling coordinates synaptic networks. Science 2005, 310(5745):113-116.

5. Volterra A, Meldolesi J: Astrocytes, from brain glue to communication elements: the revolution continues. Nat Rev Neurosci 2005, 6(8):626-640.

6. Perea $G$, Araque A: Astrocytes potentiate transmitter release at single hippocampal synapses. Science 2007, 317(5841):1083-1086.

7. Lee CJ, Mannaioni G, Yuan H, Woo DH, Gingrich MB, Traynelis SF: Astrocytic control of synaptic NMDA receptors. J Physiol 2007, 581(Pt 3):1057-1081.

8. Panatier A, Theodosis DT, Mothet JP, Touquet B, Pollegioni L, Poulain DA Oliet SH: Glia-derived D-serine controls NMDA receptor activity and synaptic memory. Cell 2006, 125(4):775-784.

9. Parpura V, Basarsky TA, Liu F, Jeftinija K, Jeftinija S, Haydon PG: Glutamate-mediated astrocyte-neuron signalling. Nature 1994, 369(6483):744-747

10. Nedergaard M, Takano T, Hansen AJ: Beyond the role of glutamate as a neurotransmitter. Nat Rev Neurosci 2002, 3(9):748-755.

11. Montana V, Malarkey EB, Verderio C, Matteoli M, Parpura V: Vesicular transmitter release from astrocytes. Glia 2006, 54(7):700-715.

12. Hamilton NB, Attwell D: Do astrocytes really exocytose neurotransmitters? Nat Rev Neurosci 2010, 11(4):227-238.

13. Jourdain P, Bergersen LH, Bhaukaurally K, Bezzi P, Santello M, Domercq M, Matute C, Tonello F, Gundersen V, Volterra A: Glutamate exocytosis from astrocytes controls synaptic strength. Nat Neurosci 2007, 10(3):331-339.

14. Kimelberg HK, Macvicar BA, Sontheimer H: Anion channels in astrocytes: biophysics, pharmacology, and function. Glia 2006, 54(7):747-757.

15. Walz W: Chloride/anion channels in glial cell membranes. Glia 2002, 40(1):1-10.

16. Takano T, Kang J, Jaiswal JK, Simon SM, Lin JH, Yu Y, Li Y, Yang J, Dienel G, Zielke HR, et al: Receptor-mediated glutamate release from volume sensitive channels in astrocytes. Proc Natl Acad Sci U S A 2005, 102(45):16466-16471.

17. Hartzell HC, Qu Z, Yu K, Xiao Q, Chien LT: Molecular physiology of bestrophins: multifunctional membrane proteins linked to best disease and other retinopathies. Physiol Rev 2008, 88(2):639-672.

18. Eggermont J: Calcium-activated chloride channels: (un)known, (un)loved? Proc Am Thorac Soc 2004, 1(1):22-27. 
19. Kunzelmann K, Milenkovic VM, Spitzner M, Soria RB, Schreiber R: Calcium-dependent chloride conductance in epithelia: is there a contribution by Bestrophin? Pflugers Arch 2007, 454(6):879-889.

20. Qu Z, Fischmeister R, Hartzell C: Mouse bestrophin-2 is a bona fide $\mathrm{Cl}(-)$ channel: identification of a residue important in anion binding and conduction. J Gen Physiol 2004, 123(4):327-340.

21. Sun $H$, Tsunenari $T$, Yau KW, Nathans J: The vitelliform macular dystrophy protein defines a new family of chloride channels. Proc Natl Acad Sci U S A 2002, 99(6):4008-4013.

22. Pifferi S, Pascarella G, Boccaccio A, Mazzatenta A, Gustincich S, Menini A, Zucchelli S: Bestrophin-2 is a candidate calcium-activated chloride channel involved in olfactory transduction. Proc Natl Acad Sci U S A 2006, 103(34):12929-12934.

23. Marmorstein AD, Marmorstein LY, Rayborn M, Wang X, Hollyfield JG, Petrukhin K: Bestrophin, the product of the Best vitelliform macular dystrophy gene (VMD2), localizes to the basolateral plasma membrane of the retinal pigment epithelium. Proc Natl Acad Sci U S A 2000, 97(23):12758-12763.

24. Chien LT, Zhang ZR, Hartzell HC: Single Cl- channels activated by $\mathrm{Ca} 2+$ in Drosophila S2 cells are mediated by bestrophins. J Gen Physio/ 2006 , 128(3):247-259.

25. Park H, Oh SJ, Han KS, Woo DH, Mannaioni G, Traynelis SF, Lee CJ: Bestrophin-1 encodes for the Ca2 +-activated anion channel in hippocampal astrocytes. J Neurosci 2009, 29(41):13063-13073.

26. Lee S, Yoon BE, Berglund K, Oh SJ, Park H, Shin HS, Augustine GJ, Lee CJ: Channel-mediated tonic GABA release from glia. Science 2010, 330(6005):790-796.

27. Hollenberg MD, Saifeddine M, al-Ani B, Kawabata A: Proteinase-activated receptors: structural requirements for activity, receptor cross-reactivity, and receptor selectivity of receptor-activating peptides. Can J Physiol Pharmacol 1997, 75(7):832-841.

28. Ramos-Mandujano G, Vazquez-Juarez E, Hernandez-Benitez $\mathrm{R}$ Pasantes-Morales $\mathrm{H}$ : Thrombin potently enhances swelling-sensitive glutamate efflux from cultured astrocytes. Glia 2007, 55(9):917-925.

29. Zhang Y, Stanton JB, Wu J, Yu K, Hartzell HC, Peachey NS, Marmorstein LY, Marmorstein AD: Suppression of $\mathrm{Ca} 2+$ signaling in a mouse model of Best disease. Hum Mol Genet 2010, 19(6):1108-1118.

30. Hires SA, Zhu Y, Tsien RY: Optical measurement of synaptic glutamate spillover and reuptake by linker optimized glutamate-sensitive fluorescent reporters. Proc Natl Acad Sci U S A 2008, 105(11):4411-4416.

31. Mothet JP, Pollegioni L, Ouanounou G, Martineau M, Fossier P, Baux G: Glutamate receptor activation triggers a calcium-dependent and SNARE protein-dependent release of the gliotransmitter D-serine. Proc Natl Acad Sci U S A 2005, 102(15):5606-5611.

32. Araque A, Parpura V, Sanzgiri RP, Haydon PG: Glutamate-dependent astrocyte modulation of synaptic transmission between cultured hippocampal neurons. Eur J Neurosci 1998, 10(6):2129-2142.

33. Malarkey EB, Parpura $\mathrm{V}$ : Mechanisms of glutamate release from astrocytes. Neurochem Int 2008, 52(1-2):142-154.

34. Yoon BE, Woo J, Justin Lee C: Astrocytes as GABA-ergic and GABA-ceptive Cells. Neurochem Res 2012: : [Epub ahead of print].

35. Chien LT, Hartzell HC: Drosophila bestrophin-1 chloride current is dually regulated by calcium and cell volume. J Gen Physio/ 2007, 130(5):513-524.

36. Gingrich MB, Junge CE, Lyuboslavsky $P$, Traynelis SF: Potentiation of NMDA receptor function by the serine protease thrombin. J Neurosci 2000 20(12):4582-4595.

37. Han KS, Mannaioni G, Hamill CE, Lee J, Junge CE, Lee CJ, Traynelis SF: Activation of protease activated receptor 1 increases the excitability of the dentate granule neurons of hippocampus. Mol Brain 2011, 4:32.

38. Junge CE, Lee CJ, Hubbard KB, Zhang Z, Olson JJ, Hepler JR, Brat DJ, Traynelis SF: Protease-activated receptor-1 in human brain: localization and functional expression in astrocytes. Exp Neurol 2004, 188(1):94-103.

39. Shigetomi E, Bowser DN, Sofroniew MV, Khakh BS: Two forms of astrocyte calcium excitability have distinct effects on NMDA receptor-mediated slow inward currents in pyramidal neurons. J Neurosci 2008, 28(26):6659-6663.

40. Hermann GE, Van Meter MJ, Rood JC, Rogers RC: Proteinase-activated receptors in the nucleus of the solitary tract: evidence for glial-neural interactions in autonomic control of the stomach. J Neurosci 2009 29(29):9292-9300.
41. Mannaioni G, Orr AG, Hamill CE, Yuan H, Pedone KH, McCoy KL, Berlinguer Palmini $R$, Junge $C E$, Lee $C J$, Yepes $M$, et al: Plasmin potentiates synaptic $\mathrm{N}$-methyl-D-aspartate receptor function in hippocampal neurons through activation of protease-activated receptor-1. J Biol Chem 2008, 283(29):20600-20611.

42. Tomimatsu $Y$, Idemoto S, Moriguchi S, Watanabe S, Nakanishi H: Proteases involved in long-term potentiation. Life Sci 2002, 72(4-5):355-361.

43. Pang PT, Lu B: Regulation of late-phase LTP and long-term memory in normal and aging hippocampus: role of secreted proteins IPA and BDNF. Ageing Res Rev 2004, 3(4):407-430.

44. Farinelli SE, Nicklas WJ: Glutamate metabolism in rat cortical astrocyte cultures. J Neurochem 1992, 58(5):1905-1915.

45. Mitrovic $A D$, Johnston $G A$ : Regional differences in the inhibition of L-glutamate and L-aspartate sodium-dependent high affinity uptake systems in rat CNS synaptosomes by L-trans-pyrrolidine-2,4dicarboxylate, threo-3-hydroxy-D-aspartate and D-aspartate. Neurochem Int 1994, 24(6):583-588.

46. Volterra A, Bezzi P, Rizzini BL, Trotti D, Ullensvang K, Danbolt NC, Racagni G: The competitive transport inhibitor L-trans-pyrrolidine-2, 4-dicarboxylate triggers excitotoxicity in rat cortical neuron-astrocyte co-cultures via glutamate release rather than uptake inhibition. Eur J Neurosci 1996, 8(9):2019-2028.

47. Bezzi P, Carmignoto G, Pasti L, Vesce S, Rossi D, Rizzini BL, Pozzan T, Volterra A: Prostaglandins stimulate calcium-dependent glutamate release in astrocytes. Nature 1998, 391(6664):281-285.

48. Bartolomeo MP, Maisano F: Validation of a reversed-phase HPLC method for quantitative amino acid analysis. J Biomol Tech 2006, 17(2):131-137.

49. Park H, Oh SJ, Han KS, Woo DH, Park H, Mannaioni G, Traynelis SF, Lee CJ: Bestrophin-1 encodes for the Ca2 + -activated anion channel in hippocampal astrocytes. J Neurosci 2009, 29(41):13063-13073.

50. Zhang Q, Pangrsic T, Kreft M, Krzan M, Li N, Sul JY, Halassa M, Van Bockstaele E, Zorec R, Haydon PG: Fusion-related release of glutamate from astrocytes. J Biol Chem 2004, 279(13):12724-12733.

51. Zhang Q, Fukuda M, Van Bockstaele E, Pascual O, Haydon PG: Synaptotagmin IV regulates glial glutamate release. Proc Natl Acad Sci U S A 2004, 101(25):9441-9446.

doi:10.1186/1756-6606-5-38

Cite this article as: Oh et al:: Protease activated receptor 1-induced glutamate release in cultured astrocytes is mediated by Bestrophin- 1 channel but not by vesicular exocytosis. Molecular Brain 2012 5:38.

\section{Submit your next manuscript to BioMed Central and take full advantage of:}

- Convenient online submission

- Thorough peer review

- No space constraints or color figure charges

- Immediate publication on acceptance

- Inclusion in PubMed, CAS, Scopus and Google Scholar

- Research which is freely available for redistribution 